\title{
Reportagem \\ Christopher Pollitt analisa a nova estrutura da gestão pública no século 21
}

Em 16 de março deste ano, a Escola Nacional de Administração Pública (ENAP) recebeu o professor-pesquisador Christopher Pollitt, da Universidade Católica de Leuven, na Bélgica. Pollitt proferiu a palestra "Rumo a uma nova estrutura de Gestão Pública no século 21", promovida pela Escola e pela Secretaria de Gestão do Ministério do Planejamento, Orçamento e Gestão

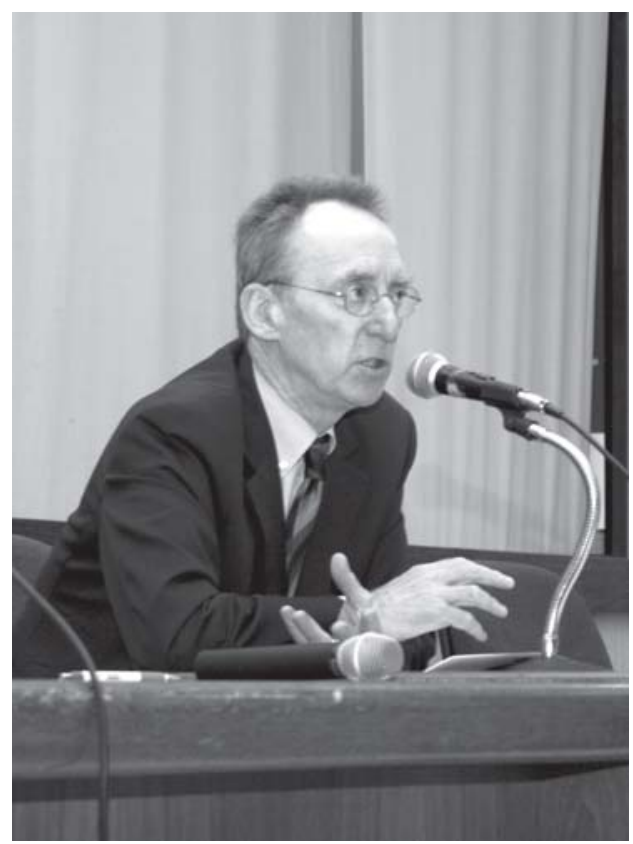

(Seges/MP), com apoio do Projeto Diálogo Setoriais Brasil-União Europeia.

Essa foi a segunda vez que o professor inglês participou de atividade na ENAP. Em novembro de 2002, ele havia proferido a palestra "Reformas da Gestão Pública: a experiência internacional pode ser transferida?", como parte do Ciclo de Seminários Internacionais: A Nova Gestão Pública em Debate evento organizado em parceria com a Seges/MP e apoio do Conselho Britânico e do Tribunal de Contas da União (TCU).

Christopher Pollitt é professorpesquisador de Gestão Pública do Instituto de Gestão Pública da Universidade Católica de Leuven e autor de livros de referência na área de administração pública. É editor da International Review of Administrative Sciences. Foi professor de Governo e reitor de Gestão Pública de Ciências Sociais na Brunel University (1990-1998) e professor de Gestão Pública na Erasmus Universiteit, em Rotterdam (1999-2006).

Esta reportagem busca sintetizar os principais tópicos apresentados pelo professor Pollitt em sua recente palestra na ENAP. 


\section{A Gestão Pública no século 21}

"O futuro da maioria dos cidadãos está associado à atuação das escolas públicas e escolas de administração pública". Assim iniciou o professor Christopher Pollitt sua palestra sobre a nova estrutura da Gestão Pública no século 21, valorizando o papel das escolas de governo e da educação como centros que atuam antecipando os problemas enfrentados diariamente pelo cidadão e pelos servidores públicos.

Para ele, falar sobre os rumos da Gestão Pública é um desafio cujo debate se inicia pela cuidadosa escolha das palavras do título de sua palestra: (em inglês Towards a New Public Administration in the 21st Century): "O título é um convite para especular sobre o futuro. A palavra rumo (towards, em inglês), no entanto, significa um movimento ainda incompleto. O que é certamente verdade quando o tema são as reformas na administração pública."

Um segundo aspecto a destacar - em decorrência de ser algo em constante mudança - é que se avalia uma estrutura (framework, em inglês), e não exatamente uma "teoria" ou "modelo", quando se discute a nova gestão da administração pública.

Pollitt justificou também o uso da preposição em (in, em inglês). Para ele não se trata de discutir uma estrutura para o século 21, mas no século 21. Essa escolha marca a diferença entre apontar o que vai acontecer em 90 anos ou mesmo as transformações no futuro próximo, sem conhecer muitos elementos novos que ainda não foram previstos, e discutir sobre como evoluem aspectos presentes em nossa atualidade e que devem persistir como parte das questões estruturais que continuarão a ser parte da vida do cidadão e dos teóricos do tema.

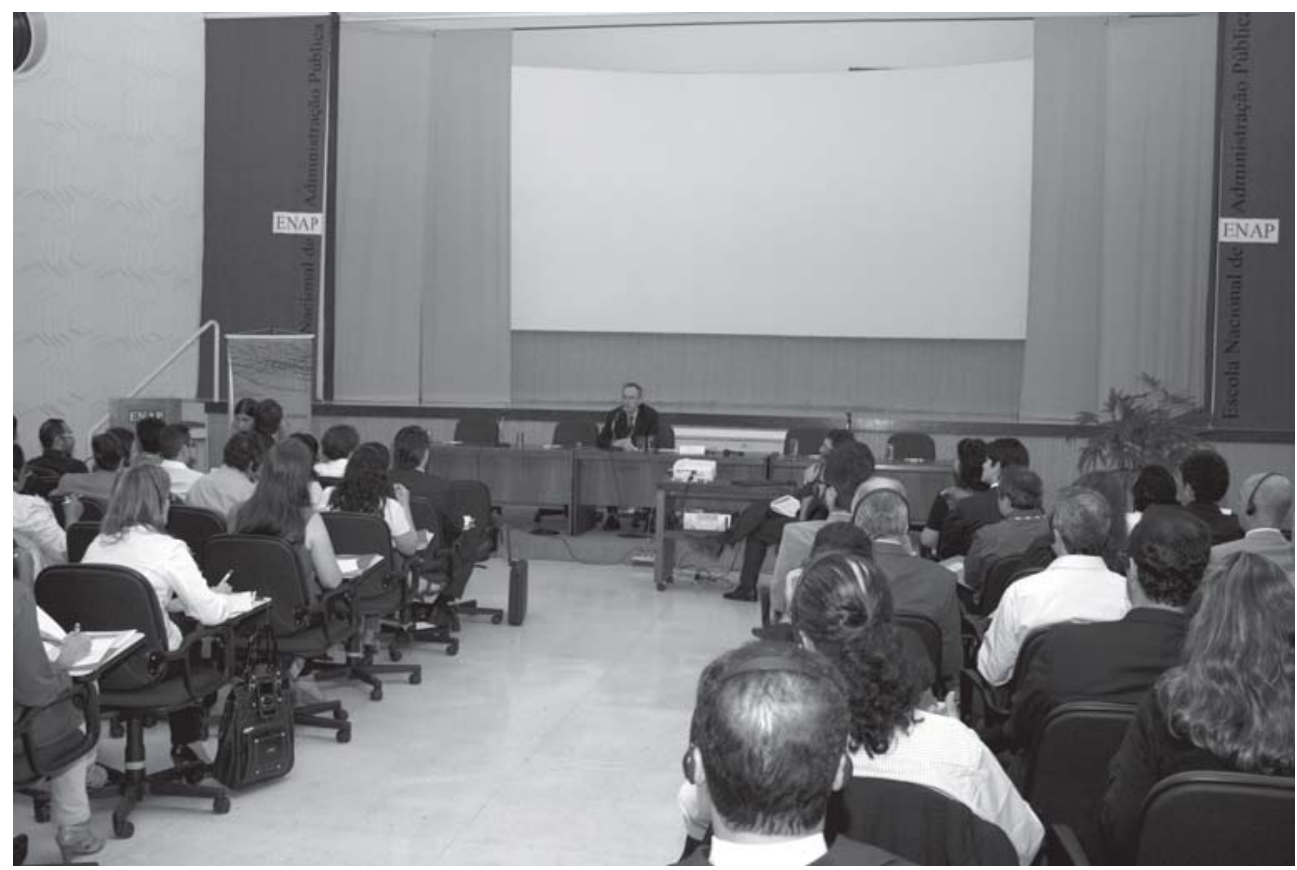

Cerca de 270 pessoas assistiram a palestra de Christopher Pollitt na ENAP. 
Nesse sentido, sua palestra foi voltada para os desafios mais gerais que ocorrem atualmente e temas de gerenciamento ou ideias de administração relacionadas a esses desafios. "Deve-se ter em mente que os antigos desafios não desapareceram. Muitos permanecem: corrupção, procedimentos burocráticos rígidos. Por essa razão, não trago uma lista exaustiva dos novos desafios", advertiu Pollitt.

\section{Novos desafios}

\section{Profundidade e duração da crise econômica e fiscal}

"Para o setor público, de modo particular na União Européia, as piores consequências da atual crise econômica e fiscal ainda estão por vir. E ainda serão sentidas por muitos anos, o que resultará em mudanças estruturais que constituirão uma nova era", acredita o professor.

Pollitt se baseia em evidências apontadas pelo Tesouro Britânico, que projeta a necessidade de cortes nos gastos públicos durante os próximos seis anos para que se consiga contornar o déficit atual. Outra previsão subsequente é a austeridade. Citando exemplos de países europeus, ele reforça a necessidade de diferenciar a gravidade da situação de cada país. O Reino Unido enfrenta um quadro particularmente ruim porque tinha um setor bancário e imobiliário de grande relevância econômica.

Os países mediterrâneos enfrentam o mesmo problema. Na Alemanha e na França, há menos dificuldades. E a Escandinávia se encontra em situação mais estável. Segundo Pollitt, mesmo países que estavam indo muito bem e com fortes setores bancário e imobiliário sofrerão problemas no setor público.

No caso do Brasil, explica Pollit, em que a crise teve menos repercussão e as consequências aparentemente não são tão diretas, "é preciso que os brasileiros tenham em mente o quadro de contenção de gastos com que trabalham os Estados Unidos e a Europa Ocidental. É preciso perceber que haverá uma mudança na psicologia da relação entre Estado e cidadão nesses lugares".

Pollitt elabora a questão mostrando que o momento de dificuldades econômicas na Europa acontecerá de forma tão severa que poderá ameaçar o modelo social europeu, conhecido como Estado de bem-estar, afetando serviços sociais de

\section{Reconhecer a complexidade dos temas graves}

Há novidades na literatura, segundo Pollitt, que destacam as maneiras de tratar as questões graves, aqueles problemas complexos que desafiam os governos. Entre esses problemas, destacam-se a violência, as drogas, a pobreza.

Iniciou-se um debate sobre a necessidade de novas iniciativas e de abordagens originais por conta das exigências mais complexas do eleitorado europeu, que se tornou mais sofisticado. O cidadão está menos interessado em partidos políticos, ele espera resultados do governo.

Como os efeitos esperados de políticas sobre tais questões acontecem no longo prazo, há um paradoxo em relação às medidas para combatê-las, pois estas são de caráter mais imediatista. Os eleitores, no entanto, querem resultados. Assim, cresce o debate sobre quais são as formas adotadas pelos diferentes governos para tratar cada um desses temas. 
base, como saúde, educação e as aposentadorias, entre outros benefícios. Tais medidas causarão grande impopularidade, podendo provocar crises de legitimidade para alguns governos.

\section{Cidadania mais ativa e educada, menos partidária}

Os cidadãos estão diferentes de gerações pregressas. São mais ricos, mais educados, têm expectativas, são impacientes. Não se impressionam facilmente com ordens nem sistemas hierárquicos. São pessoas com cada vez maior capacidade de organização e mobilização.

As tecnologias atuais auxiliam e potencializam as novas habilidades. Como exemplo, Pollitt destaca que é possível organizar uma mobilização de milhares de pessoas em Londres em menos de 24 horas graças a recursos como a internet. Cidadãos se reúnem em blogs que captam em poucos dias centenas de milhares de assinaturas, que podem ser apresentadas ao governo. A nova realidade significa um novo ambiente para políticos, que carrega em si desafios imprevistos.

\section{Mídia mais rápida e agressiva (peixe no aquário)}

A partir do novo perfil do cidadão, estabelece-se uma nova identidade para a mídia. A mudança ocorre em duas dimensões. Uma pode ser explicada pela relação inédita entre a mídia, que se tornou mais ousada, e a política. Isso produziu uma atitude cética por parte da imprensa, em relação ao governo, em todos os países.

A segunda transformação aconteceu no tamanho e nos recursos técnicos da mídia. Ela se tornou uma indústria de grande porte. Pollitt ressaltou que, em estudo feito na Dinamarca, um levantamento com servidores de carreira de ministérios e agências governamentais em altos cargos sobre a adequação do nível de cada função com a capacitação recebida pelos funcionários apontou que eles se sentiam seguros em seus papéis. A única ressalva mencionada com frequência foi o despreparo para responder às demandas da mídia.

Nesse mesmo estudo, descobriu-se que a mídia dinamarquesa empregava três vezes mais que há 20 anos. Existem mais cursos universitários de graduação e pósgraduação em jornalismo. "A mídia está maior, mais ágil, tem mais empregados, mais canais de comunicação e mais ousadia perante o governo. $\mathrm{O}$ fato é de relevância dentro da estrutura da administração pública porque se reflete diretamente nas relações entre políticos e funcionários do alto escalão do governo, além de ter impacto na relação de ambos os lados com os cidadãos", explicou Pollitt. O professor usou a expressão "peixe no aquário" para caracterizar a maneira como os integrantes do governo são submetido a uma constante vigilância.

\section{Escala internacional de desafios (mudanças climáticas, crime organi- zado, acordos comerciais) \\ Pollit destacou a natureza internacional} de certos problemas que a administração pública enfrenta como outro amplo desafio de destaque. Há questões que não se restringem à fronteira, mesmo num país enorme como o Brasil ou em espaço político como a União Europeia. Entre os assuntos, há os mais explícitos, como as mudanças climáticas e acordos de comércio internacional, e outros menos patentes, que é o caso do crime organizado. É necessário fortalecer as relações entre as polícias federais dos países, por exemplo, com intercâmbio de dados e possibilidade de uso comum de ferramentas para coibir 
os crimes de caráter transnacional. Assim, a escala internacional tornou-se um novo item na agenda da administração pública.

\section{Maior reconhecimento da impor- tância da motivação para o serviço público}

O último novo desafio geral apontado por Pollitt trata da importância da valorização do serviço público, questão recorrente no meio acadêmico. De encontro à teoria da escolha racional e do agente principal, que teve auge nas décadas de 80 e 90 do século XX, principalmente nos Estados Unidos, há evidências sugerindo que a forma como a maioria dos servidores públicos pensa e se comporta é ainda mais complexa. Surge então a ideia de que servidores públicos têm motivação intrínseca à gestão pública, um dos questionamentos mais disseminados em vários países e no meio acadêmico. Para eles, a recompensa vai além da remuneração. Há satisfação em saber que de alguma forma, em sua visão, ele serve ao interesse público.

Destaca-se a valorização, presente em todo serviço público, mas evidenciada principalmente nas áreas de saúde e educação. Há pesquisas empíricas com o intuito de medir a extensão desse fenômeno. Para Pollitt, no entanto, a atenção deve ser voltada à existência de tal dimensão devido à importância desse recurso para a administração pública. "A motivação intrínseca ao serviço público deve ser preservada onde foi detectada e incentivada nos espaços em que ainda não foi percebida", afirmou.

É preciso, segundo o professor, enxergar os servidores públicos como pessoas que respondem mais do que apenas aos incentivos da remuneração. O salário se torna importante até determinado ponto, em especial para os servidores que tem baixa remuneração, mas a partir da quantia considerada adequada, a motivação se torna crucial para melhorar o desempenho. É preciso atender às aspirações mais elevadas do servidor público.

\section{Alguns temas administrativos atuais}

\section{Abordagens de governo unificado, como um todo}

Relacionados aos desafios mais amplos encontram-se temas de gestão mais específicos. Dentro dessa linha está a abordagem do governo como um todo, assunto vinculado à ideia dos temas graves. O governo unificado envolve coordenação horizontal entre diferentes setores do serviço público em níveis de governo diversos. Abrange também articulação estreita entre governo e outras partes da sociedade como associações, empresas, organizações voluntárias, sempre com enfoque na horizontalidade.

Essa é uma proposta difundida em vários países que, segundo Christopher Pollitt, provavelmente crescerá nos próximos anos. O auxílio técnico proporcionado por novas tecnologias, que resulta em facilidades como o governo eletrônico, será capital dentro do processo de tornar unificada a administração pública. Para exemplificar, Pollitt lembrou a reunião de serviços de diversos setores do governo inglês num site comum, que alimenta o banco de dados de cada agência envolvida.

"Em situações mais complexas, significa redirecionar investimentos de maneira a aperfeiçoar os resultados. Com tal intuito, articulam-se autoridades de diferentes áreas para implantar a política mais indicada. Apreende-se que há casos em que a complexidade da situação exige a visão do 
todo para enxergar a origem do problema e como melhor preveni-lo", explicou.

Segundo Pollitt, o programa de melhora no serviço de saúde pública no subúrbio de Glasgow, no Reino Unido, exemplifica essa questão. Para mitigar o quadro, o governo repassou a verba para as autoridades de saúde. Estudos posteriores comprovaram que se a mesma quantia fosse aplicada em habitação, o resultado seria mais significativo. Isso devido ao fato de a dificuldade em saúde advir da precariedade da habitação e da dieta alimentar na região.

Assim, um dos grandes desafios da administração pública, na opinião de Pollitt, é a necessidade de tornar o governo horizontal, com a visão do todo. Mudança que se mostra benéfica em projetos-piloto de unificação de resposta no nível nacional.

\section{Fortalecendo administração por desempenho e tomada de decisões baseada em evidências}

Em segundo lugar entre os desafios relacionados, está o fortalecimento da gestão por desempenho e a tomada de decisões baseada em evidência. Esse é um assunto conhecido, que tem sido discutido há mais de uma década. A política baseada em evidência (EBP, sigla em inglês) foi adotada na Inglaterra pelo ex-primeiroministro Tony Blair.

Num primeiro momento, o meio acadêmico recebeu positivamente a novidade, mesmo que a necessidade de conceituar o termo evidência tenha causado debate entre pesquisadores. A dificuldade maior se apresentou na tentativa de colocar em prática a EBP quando as evidências vão em direção oposta ao programa de governo do partido que vence as eleições ou às declarações pregressas dos políticos eleitos para cargos públicos.

Pollitt usa a sentença de morte como exemplo. Abolida na Inglaterra há décadas, foi apontada em pesquisas de opinião, como recebendo o apoio de $75 \%$ da população. De acordo com a política baseada em evidência, o resultado significa que os políticos precisam restabelecer a pena de morte no país. Para o fazerem, no entanto, teriam de ignorar os inúmeros estudos que apontam que a sentença de morte é ineficiente na diminuição de crimes.

Haveria, ainda, o embate com o estatuto da União Europeia, que determina aos Estados-membros não adotar a pena de morte. Pollitt ressalta, dessa forma, que a política baseada em evidências é um desafio para os políticos, que podem se encontrar em situações desconfortáveis.

\section{Mais transparência e responsabi- lização \\ Outro tema destacado foi a necessidade} de maior transparência e responsabilização. Pollitt alerta para o risco de se apresentar a transparência como resposta definitiva para todas as questões de atrito entre a administração pública e o cidadão. A ideia de transparência tende a ser considerada como a possibilidade de dar aos cidadãos acesso a todo e qualquer detalhe dos processos que levaram às decisões que políticos e servidores públicos realizaram em seu nome.

Pollitt se disse cético em relação a essa visão ao observar que as leis de liberdade de informação, disseminadas amplamente nos últimos 20 anos no Canadá, Estados Unidos e Reino Unido, não são usadas por milhares de cidadãos interessados em detalhes. As pesquisas mostram que cerca de $70 \%$ das solicitações são usados pela mídia e para servir a interesses corporativos e não aos cidadãos. 
O caso do Canadá foi por ele utilizado como emblemático. Todo cidadão canadense pode exigir ter acesso ao conteúdo de qualquer mensagem eletrônica enviada por servidores públicos. Em tese, é possível ver todos os documentos encaminhados aos ministros. O resultado de tamanha visibilidade pode levar a que as pessoas parem de enviar documentos e e-mails e passem a se reunir em grupos de conversa nos corredores.

Para Pollitt, não se pode desconhecer que a política exige algum tipo de confidencialidade. Há situações em que os políticos têm de aceitar o meio termo. Momentos em que precisam abrir mão de algo para obter um resultado mais amplo em troca. As reuniões de cúpula na Europa exemplificam esse conceito. $O$ que acontece na discussão entre os representantes de cada país não é disponibilizado para a mídia. Já o resultado acordado é amplamente publicado, seguido de declarações dos atores envolvidos, mas detalhes da negociação permanecem em sigilo.

O pesquisador alerta que existe, sim, a transparência benéfica. Uma solicitação em órgão administrativo, por exemplo, pode conter um serviço de acompanhamento. Em alguns casos, com a mesma informação do servidor, um sumário das legislações relativas ao assunto, o andamento da situação. "A implantação de serviços dessa natureza faz parte do processo de mudar a relação entre cidadão e Estado, em que o último deixa de ser um espaço inatingivel com o intuito de punir para se equiparar ao cidadão e, assim, ajudá-lo. É a ideia do Estado prestador de serviço".

\footnotetext{
Mais treinamento para oficiais em contextos internacionais

O próximo tema retoma o desafio das questões de escala internacional. Com o aumento da circulação devido à quebra das
}

fronteiras, faz-se necessário treinamento específico para os funcionários que trabalham em contextos internacionais. Segundo Pollitt, cada país trata isso de maneira diferente, mas há bons exemplos.

Ao trabalhar para o governo finlandês na década de 1990, Pollitt participou das mudanças ocasionadas no governo ao aderir à União Europeia em 1999. Os três primeiros escalões da administração pública passaram por capacitação que incluía não somente cursos sobre as novas regras do governo, mas também aulas sobre as questões culturais relacionadas aos outros membros. Os gestores públicos levaram esse nível da preparação a sério. Estudaram idiomas, fizeram simulações de debates.

No ensino da administração pública nos níveis de mestrado ou doutorado, vêse que os alunos têm interesse em trabalhar em instituições internacionais, como as agências da União Europeia, organizações de caridade internacionais, Banco Mundial, Organização Mundial do Comércio (OMC). O assunto desperta interesse em jovens talentosos, que devem ser preparados para agir na área.

\section{Gestão de novas tecnologias}

Dentro da perspectiva da estrutura para o século 21, Pollitt destaca a gestão de novas tecnologias. O pesquisador fez um projeto há três anos sobre o impacto das novidades técnicas na administração pública. A conclusão foi que a tecnologia tem efeito profundo na forma como a administração pública funciona, com possibilidade de simplificar muitos processos. Pollitt exemplifica enumerando as transformações no trabalho policial durante os últimos 15 anos.

Hoje a ciência permite encontrar criminosos de maneira mais simples e eficiente. Nesse exemplo assim como em 
outras áreas, as novas tecnologias influenciam a gestão governamental em níveis que vão além dos serviços eletrônicos do governo. Esse processo deve se acentuar nos próximos 10 anos, mas já é realidade em muitos países, em que a maior parte das transações pode ser feita eletronicamente.

\section{Mudança de cidadãos por meio de direcionamentos brandos}

Uma ideia emprestada da economia e da psicologia é a de direcionamentos brandos para tratar dos temas graves e mudar os maus hábitos da população. Evidências mostram que um ataque frontal a esses problemas funciona menos que um direcionamento persistente. Um exemplo são as políticas de combate ao consumo de álcool por motoristas, problema que causa milhares de mortes no mundo. Além das campanhas de alerta, faz-se necessária a introdução de iniciativas de menor repercussão, como aumentar o preço de bebidas alcoólicas e uso de bafômetro para auxiliar as campanhas educativas.

É a tática de reduzir a área de conforto das pessoas que têm determinado comportamento. No exemplo do consumo de álcool antes de dirigir, o Reino Unido conseguiu diminuir substancialmente a incidência de acidentes automotivos relacionados ao consumo de álcool no período de uma geração. Incutiu-se nos jovens o comportamento de uso de táxi e monitoramento de um cidadão sobre o outro, sempre com o auxílio dos direcionamentos brandos. O que se apreende é o uso de iniciativas criativas em lugar da punição para garantir o cumprimento da lei.

\section{Resposta à diversidade}

Pollitt também tratou em sua palestra do tema da diversidade. Ele conceitua diversidade como rótulo para tudo aquilo que diferencia um cidadão do outro: etnia, religião, saúde física e mental, deficiências, idade. Christopher Pollitt disse considerar lento o processo de avanço pela valorização da diversidade. Em seguida, enumerou questões tidas como importantes. Em primeiro lugar, salientou que apenas uma parcela da população não faz parte de pelo menos grupo considerado "minoria". A probabilidade é que todo cidadão se encaixe em alguma categoria pelo menos por um período da vida.

Assim, os sistemas públicos têm que se adaptar. Ele destacou que uma nova lei no Reino Unido introduz um princípio geral de que locais públicos e estabelecimentos comerciais têm de oferecer um ambiente propício a qualquer tipo de deficiência. E também que os sites do governo na internet, por exemplo, têm opções de informações em outras línguas, além do inglês. "Dar acesso à informação para cidadãos na língua deles é um exemplo da atenção que deve ser dada pela administração pública à diversidade. É uma demonstração pública de respeito às diferenças", enfatizou Pollitt. A maior vantagem da tecnologia da informação, segundo o pesquisador, é a facilidade da implantação de mudanças como essas. 